UDC: $811.163 .41 ’ 367.625$

$811.134 .2 ’ 367.625$

DOI: https:// doi.org/10.18485/beoiber.2021.5.1.1

Milica Lilić1

Universidad de Sevilla

España

\title{
DIDÁCTICA DEL PASADO. EL PRETÉRITO EN SERBIO Y SUS FORMAS CORRESPONDIENTES EN ESPAÑOL
}

\begin{abstract}
Resumen
Partiendo de la predominancia del pretérito en serbio, como tiempo verbal usado con mayor frecuencia para expresar acciones y estados del pasado, el presente estudio pretende buscar sus formas correspondientes en español, dependiendo de su uso sintáctico y la finalidad del enunciado. Así, a través de una serie de ejemplos, se explicarán los cuatro tipos del pretérito en serbio (indicativo, relativo, cualitativo y modal) y se analizarán sus tiempos y perífrasis verbales correspondientes en español. Asimismo, se pondrá un énfasis en los usos del pretérito truncado en serbio, comparándolo con sus formas equivalentes en español. Todo este análisis demostrará que el uso del pretérito en serbio es tan extendido que se hace necesario recurrir a la mayoría de las formas verbales en español para abarcar todos sus usos y transmitir un comunicado determinado de forma correcta. Asimismo, los resultados del estudio demostrarán que el mismo puede interpretarse como una herramienta didáctica para la enseñanza del español como lengua extranjera.

Palabras clave: pretérito en serbio, formas correspondientes en español, tiempos verbales, perífrasis verbales, didáctica del pasado.

\section{DIDACTICS OF THE PAST. THE PAST TENSE IN SERBIAN AND ITS CORRESPONDING FORMS IN SPANISH}

\section{Summary}

Starting from the dominance of the past tense in Serbian, as the most frequently used tense to express actions and states of the past, this study tries to find its corresponding forms in Spanish, depending on its syntactic use and the purpose of the statement. Thus, through a series of examples, the four types of the past tense in Serbian will be explained (indicative, relative, qualitative and modal) and their corresponding tenses and verbal periphrasis in Spanish will be analyzed. Likewise, an emphasis will be placed on the uses of the truncated past tense in Serbian, comparing it with its equivalent forms in Spanish.
\end{abstract}

${ }^{1}$ mlilic@us.es 
The analysis shows that the use of the past tense in Serbian is so widespread that it is necessary to resort to most of the verb forms in Spanish to cover all its uses and to transmit a particular statement correctly. Likewise, the results of the study show that it can be interpreted as a didactic tool for teaching Spanish as a foreign language.

Key words: past tense in Serbian, corresponding forms in Spanish, verb tenses, verb periphrasis, didactics of the past.

\section{Introducción}

Dependiendo de la situación en la que se utilicen, el contexto lingüístico específico al que pertenecen, la actitud del hablante y el objetivo que se quiera lograr con el mensaje, los significados de los tiempos verbales adquieren sus particulares. Esta es la base de la diferencia entre el tiempo gramatical y el tiempo real de la acción (Pavón Lucer 2007: 114). Así, las reglas gramaticales y lingüísticas que condicionan el uso de un determinado tiempo verbal en el idioma serbio coincidirán en algunos casos, pero en otros diferirán significativamente de las establecidas en español. Tal situación lingüística forma parte del objeto del presente estudio, dando lugar a un análisis comparativo de los tiempos verbales usados en serbio y español para denotar el pasado.

\section{Metodología}

Para cumplir con el objetivo establecido, se partirá de un enfoque analítico que ofrecerá un resumen de los tiempos verbales usados para denotar el pasado en serbio, por una parte, y en español, por otra. Tal estudio permitirá establecer las bases necesarias para contrastar los usos del pretérito en serbio y sus formas correspondientes en español. Para ello, con el objetivo de facilitar la interpretación de los datos y corroborar el razonamiento teórico, se recurrirá a una serie de ejemplos, recogidos principalmente de Gramatika srpskog jezika, manual de referencia para estudiar los aspectos más relevantes de la gramática serbia, incluidos los tiempos verbales. Este corpus irá seguido de sus traducciones correspondientes al español, realizadas dependiendo de la finalidad de cada enunciado y su uso sintáctico, tras la consulta de estudios relevantes y, en especial, del Diccionario de la Real Academia Española, con el objetivo de aportar a la mayor fiabilidad de los ejemplos ofrecidos.

Cabe señalar, además, que, aparte de ofrecer un análisis contrastivo entre los cuatro tipos del pretérito en serbio y sus formas correspondientes en español y, por tanto, servir de aportación a la comunidad académica, el presente estudio pretende constituirse como una guía didáctica para profesores serbios de español como lengua extranjera, esto es, 
utilizarse en el aula con estudiantes de nivel avanzado de español. Este objetivo se hace alcanzable teniendo en cuenta, en especial, los ejemplos ilustrativos que acompañan cada uno de los usos del pretérito en serbio. Esto quiere decir que el estudio puede interpretarse como una herramienta de enseñanza de tiempos y perífrasis verbales en español y como un manual autodidáctico para aquellos alumnos interesados en relacionar sus conocimientos de la gramática serbia con la española.

\section{Tiempos verbales para marcar el pasado en serbio}

La existencia de un tiempo que marca acciones, estados y eventos del pasado forma parte del sistema verbal de la mayoría de los idiomas del mundo. El idioma serbio, en particular, cuenta con más de una forma verbal de este tipo, precisamente para evitar la ambigüedad de expresión y transmitir claramente el mensaje, así como por razones estilísticas, es decir, para enriquecer el idioma en sí. Así, en serbio se utilizan pretérito (perfekat), aoristo (aorist), imperfecto (imperfekat) y pluscuamperfecto (pluskvamperfekat) para denotar el pasado, siendo los primeros dos los que predominan en gran medida, mientras que el imperfecto y el pluscuamperfecto se dan esporádicamente:

- Prošao sam pored stare kuće, ali nisam osetio nikakvu setu. (pretérito)

- Prođoh pored stare kuće, ali nikakvu setu ne osetih. (aoristo)

Aunque ambas oraciones en los ejemplos anteriores en principio transmiten el mismo mensaje, difieren en expresividad, de manera que el aoristo le da un sentimiento más subjetivo al enunciado. El uso del aoristo, además, tiene una connotación arcaica, por lo que el pretérito se ha convertido en el tiempo verbal predominante para marcar acciones del pasado. En su estudio de los sistemas temporo-aspectuales en serbocroata y en español, Bajić Nikolić y Alonzo Zarza explican ese dominio del pretérito en serbio afirmando que «el tiempo español es fuertemente referencial y el serbocroata apenas lo es, incluso la referencialidad del aoristo puede mitigarse con elementos no verbales, lo que explica su retroceso en la lengua moderna. Por las mismas razones han desaparecido el imperfecto y pluscuamperfecto» (2006: 285).

Partiendo de esta base, se deduce que es prácticamente imposible transmitir matices y diferentes niveles de experiencia de alguna acción del pasado usando siempre el mismo tiempo verbal. Por ello, el idioma serbio invoca otros medios lingüísticos, entre ellos el aspecto gramatical (glagolski vid, en su terminología serbia), que implica la diferencia en la duración de la acción, estado o evento expresados por el verbo (Stanojčić i Popović 2004: 104). En ese sentido, dependiendo del estado del desarrollo de la acción, se distinguen los verbos perfectivos (svršeni), imperfectivos (nesvršeni) y de aspecto doble (dvovidski). Estos 
últimos solo se pueden determinar con precisión en una oración, ya que tienen la misma base léxica y la misma forma para ambos aspectos. Así, los verbos čuti, videti y večerati tendrán solo una forma correspondiente en español («oír», «ver», «cenar», respectivamente). Por otro lado, para los verbos españoles «caer», «escribir», «sentarse», en serbio hay varios verbos correspondientes, entre ellos: pasti (perf.) y padati (imperf.); napisati (perf.), prepisati (perf.), ispisati (perf.) y pisati (imperf.); sesti (perf.), sedati (imperf.) y sedeti (imperf.). Así, el problema de usar distintos verbos en serbio, dependiendo de la duración, o bien, la limitación de la acción, se puede resolver en español usando distintos tiempos verbales, como en los ejemplos:

- Pisao je knjigu.

- Napisao je knjigu.
Escribía un libro. (duración de la acción)

Escribió un libro. (limitación de la acción)

Otra técnica usada en serbio para hacer referencia más precisa al pasado son las llamadas rečce. Esta parte invariable de la oración implica la actitud personal del hablante hacia lo que se dice en la oración (Stanojčić i Popović 2004: 128). En algunos casos en español, es suficiente usar un tiempo verbal adecuado para transmitir el mismo mensaje que se consigue con una determinada rečca en serbio:

- Ko li je zvao Marka?

- ¿Quién le habrá llamado/llamaría a Marco?

\section{Tiempos verbales para marcar el pasado en español}

En español se distinguen principalmente tres tiempos verbales absolutos, en función de la relación que se establezca entre la ejecución de la acción y el momento del habla. Si la acción precede al momento del habla, hablamos del pretérito, si lo sigue, se trata del futuro, y si estos dos coinciden, es el presente (Pavón Lucer 2007: 114). Estos tres tiempos se ramifican posteriormente en relativos. Así, según aclara Díaz Rubio y Carmena (1885: 36), «tomando como punto de partida el presente, el pretérito se define por la anterioridad». El pretérito, por tanto, se refiere a una acción que ha tenido lugar antes de alguna otra acción, o bien, antes del momento presente.

A diferencia del serbio donde claramente predomina un tiempo verbal para marcar acciones pasadas, en español destacan cuatro pretéritos relativos: pretérito perfecto próximo, pretérito perfecto remoto, pretérito imperfecto y pretérito pluscuamperfecto (RAE 1999: 65-66). Estos tiempos no se diferencian entre ellos solo en términos de estilo, sino que su uso suele estar condicionado por reglas gramaticales (por ejemplo, por la concordancia de tiempos). Sin embargo, estas funciones no están estrictamente determinadas, por lo que en determinadas situaciones del habla es posible utilizar más de 
un tiempo verbal y transmitir relativamente el mismo mensaje -aunque no exactamente el mismo-. Por eso se hace necesario distinguir los cuatro pretéritos y señalar sus características principales.

\subsection{Pretérito imperfecto}

Indica que la acción que transmite el verbo se comporta como un presente en comparación con otra acción pasada, o bien, indica la duración de la misma (RAE 1999: 53). En ese sentido, también se puede utilizar la perífrasis verbal «estar + gerundio», como en el siguiente ejemplo:

- Llegó mi hermano justo cuando yo le escribía/estaba escribiendo.

Asimismo, este pretérito se utiliza a menudo para indicar el marco en el que ocurren los hechos pasados, o bien, para interrumpir la narración y describir ciertas características de personas o fenómenos del pasado (Garcés 1997: 33):

- Abrí la puerta y vi a un hombre. Era alto y llevaba un traje oscuro.

\subsection{Pretérito perfecto remoto}

A diferencia del pretérito imperfecto, este se refiere a una acción que remite a un determinado marco del pasado y que ha terminado (RAE 1999: 54). En narración, marca una secuencia de eventos o una especie de enumeración, como queda reflejado en el siguiente ejemplo:

- Abrí la puerta y vi a un hombre. Era alto y llevaba un traje oscuro.

\subsection{Pretérito perfecto próximo}

En general, se refiere a una acción del pasado que no está estrictamente determinada por un determinante de tiempo, que está cerca del momento presente o está relacionada de alguna manera con él (RAE 1999: 53).

- Pedro ha estado en Italia varias veces.

Garcés señala también que el uso de pretérito perfecto próximo es obligatorio en oraciones condicionales características por la presencia de la conjunción «si», donde el verbo de la oración principal se refiere al tiempo futuro (1997: 51), como en el ejemplo: 
- Si no le has explicado bien la dirección, no encontrará la calle.

También se utiliza para indicar acciones que tuvieron lugar justo antes del momento del discurso. En este caso, el pretérito puede ser reemplazado por la perífrasis «acabar de + infinitivo» (Garcés 1997: 52). El uso de esta perífrasis ya incluye el determinante de tiempo, por lo sería redundante especificarlo de forma explícita:

Hace un momento he hablado con él. = Acabo de hablar con él.

*Hace un momento acabo de hablar con él.

La distinción entre el pretérito perfecto próximo y el remoto se ha perdido en la mayoría de países latinoamericanos y, según aclara María Garcés, también en Galicia y Asturias en España (1997: 52). En todas estas regiones, la primacía le perteneció al pretérito remoto. Sin embargo, el uso del pretérito perfecto próximo no ha desaparecido por completo en los países de América Latina. En ocasiones se utiliza cuando el hablante quiere enfatizar una determinada acción que es especialmente importante en la narración y que surge como una especie de conclusión (Garcés 1997: 52):

- Salió precipitadamente de la casa, corrió hacia la orilla del mar y al llegar allí, ¿te imaginas a quien se ha encontrado?

El español de la España peninsular, por su parte, no admite este uso del pretérito perfecto próximo.

\subsection{Pretérito pluscuamperfecto}

Se refiere a una acción que precedió a otra acción del pasado (RAE 1999: 55):

- Yo había leído ya la carta cuando me dieron la noticia.

Tanto el pluscuamperfecto como el imperfecto se utilizan a menudo en la concordancia de tiempos, como es el caso del discurso indirecto en el que el verbo introductorio está marcado por un pasado terminado:

Pedro: ¡Ya tengo el libro

Pedro: Ya he leído ese libro.

Pedro exclamó que ya tenía el libro. Pedro dijo que ya había leído ese libro. 


\section{El pretérito en serbio y sus formas correspondientes en español}

Como ya se ha señalado, el pretérito es el tiempo más utilizado en el idioma serbio cuando el enunciado se refiere al pasado, es decir, a eventos que ocurrieron antes del momento en que el hablante los anuncia. Sin embargo, su finalidad en el lenguaje es mucho más amplia y se relaciona con diferentes usos sintácticos (Stanojčić i Popović 2004: 386). Cada uno de estos usos encontrará su equivalente en español, ya sea en uno de los cuatro pretéritos o entre otras formas y perífrasis verbales. En aras de un análisis comparativo más fácil y detallado, a continuación, se analizará por separado cada uno de los usos del pretérito en el idioma serbio y se comparará con sus formas correspondientes en español.

\subsection{Pretérito indicativo (indikationi perfekat)}

Representa la forma más común para marcar el pasado y se refiere a eventos que ocurrieron antes del momento del habla, donde el hablante determina el momento de la realización de esas acciones directamente de acuerdo con el momento de habla, independientemente del momento exacto en el que se realizaron (Stanojčić i Popović 2004: 386). Este tipo de pretérito se utiliza principalmente en situaciones que el hablante comunica directamente.

- Učenici su šetali parkom celo popodne i oblilazili razne muzeje.

- Los alumnos paseaban por el parque toda la tarde y visitaban varios museos. estaban paseando estaban visitando

El aspecto gramatical imperfectivo de los verbos šetati y obilaziti corresponde al pretérito imperfecto de los verbos «pasear» $\mathrm{y}$ «visitar». Otra solución a la traducción del ejemplo mencionado sería recurriendo a la perífrasis verbal «estar + gerundio», que confiere a la acción una cierta duración. Esto quiere decir que dicha perífrasis no puede utilizarse para acciones que no tengan una cierta continuidad o duración. Para expresar tal tipo de situaciones, en serbio se utilizan con mayor frecuencia los verbos del aspecto gramatical perfectivo, y en español se recurre al uso de otros tiempos verbales:

- Učenici su prošetali parkom, a potom su neki i zaspali.

- Los alumnos pasearon por el parque, y después algunos se quedaron dormidos. 
En el caso del verbo prošetati, en español se ha utilizado el pretérito perfecto remoto («pasearon»), ya que implica una acción que se ha completado en el pasado. Como la oración es de carácter neutro (no existen determinantes que sitúen el momento de la acción en un determinado marco temporal), también es posible el uso del pretérito perfecto próximo («han paseado»). Por otra parte, el verbo zaspati se ha traducido con la perífrasis «quedarse + participio pasado», que marca el final de una acción.

Por otra parte, si a la oración en serbio se le añadiera un adverbio de duda para darle al enunciado una cierta dosis de incertidumbre y probabilidad (por ejemplo, možda, verovatno), las formas verbales usadas permanecerían iguales. Sin embargo, tal alteración en español también afectaría directamente al uso de los tiempos verbales, ya que algunos de los marcadores discursivos requieren el uso de subjuntivo. Este modo verbal está siempre condicionado por la presencia de otra expresión (explícita o elíptica), situada antes o después del propio subjuntivo («puede que», «es obvio que», «es importante que», «es inevitable que» etc.) (RAE 1999: 51), o alguien otro elemento sintáctico (negaciones en algunos casos o ciertos adverbios como «tal vez» o «quizás») (Pavón Lucer 2007: 116). El uso de todos los tiempos verbales en subjuntivo coincide con las reglas de su uso en indicativo, por lo que en ese caso las oraciones del ejemplo anterior serían:

- Učenici su verovatno prošetali parkom, a posle su možda i zaspali.

- Lo probable es que/tal vez/quizás los alumnos pasearan/hayan paseado por el parque, y después, puede que se quedaran/hayan quedado dormidos.

$\mathrm{Al}$ expresar una intención que no se ha realizado en el pasado, en serbio se usa el predicado complejo, donde el verbo incompleto en pretérito va acompañado del infinitivo o la construcción «da + presente»:

- Hteo sam doći/da dođem na proslavu, ali je bilo kasno.

- Iba a ir a la fiesta, pero se me hizo tarde.

\section{se me ha hecho tarde}

La forma más adecuada en español para indicar la intención no realizada en el pasado es la perífrasis «ir + a + infinitivo», donde el verbo «ir» siempre aparece en pretérito imperfecto. Después de esta oración es común el uso de la conjunción "pero», que introduce una explicación del porqué de la acción no realizada (se hizo tarde / se ha hecho tarde).

Además, la expresión de deseo, necesidad o arrepentimiento por una acción no cumplida en el pasado es la misma en serbio en términos de tiempos verbales, independientemente de los sujetos (el verbo introductorio va seguido de la construcción $d a+$ pretérito), mientras que en español no es así, como se indica claramente a continuación: 
- Voleo bih da sam došao na tooju proslavu.

Me gustaría haber ido a tu fiesta.

(a mí) (yo)

- Voleo bih da si došao na moju proslavu.

Me gustaría que hubieras venido a mi fiesta.

(a mí)

(tú)

Es decir, si en español el sujeto de un verbo expresado por un condicional y un verbo que expresa una acción no realizada coinciden $(\mathrm{yo}=\mathrm{yo})$, la única solución correcta que corresponde al pretérito del idioma serbio es el infinitivo perfecto («haber ido»). En caso de que estos sujetos difieran (yo $\neq$ tú), el condicional debe ir seguido del conector «que» y el pretérito pluscuamperfecto. Como el verbo «gustar» del ejemplo anterior pertenece al grupo de aquellos verbos que requieren el uso de subjuntivo, la forma final que corresponde al pretérito en serbio es el pluscuamperfecto de subjuntivo («hubieras venido»).

El siguiente ejemplo indica que el pretérito en serbio puede corresponder al presente de indicativo en español:

- Zamalo nisam pao.

- Por poco me caigo.

De hecho, el presente puede denotar el pasado como en el ejemplo anterior, en los casos en los que no se ha cumplido la acción situada en el marco del pasado (Garcés 1997: 23). Se usa con los términos «por un poco», «por poco», «a poco más». Los siguientes ejemplos reflejan una situación similar:

Zamalo nisam zakasnio na konferenciju.

Por poco llego tarde a la conferencia.
Zamalo da zakasnim na konferenciju. Por poco no llego a la conferencia.

Ambos ejemplos transmiten esencialmente el mismo mensaje (el orador llegó a la conferencia justo cuando comenzó), pero en el idioma serbio, la presencia o ausencia de la negación condicionó el uso de diferentes tiempos verbales, mientras que en español no fue así.

El pretérito también se usa en serbio en oraciones exclamativas en las que el hablante lamenta algo del pasado que podría haber evitado, pero en el momento del discurso es demasiado tarde para corregirlo. En español, en este tipo de situaciones se implementará el condicional, o bien, el pluscuamperfecto de subjuntivo: 
- Zašto nisam učio španski u školi!

- ¡Por qué no estudiaría español en el colegio! / ¡Ojalá / Si solo hubiera estudiado español en el colegio!

\subsection{Pretérito relativo (relativni perfekat)}

Aparece principalmente en la narración y es bastante similar al pretérito indicativo, pero la diferencia se basa en el hecho de que entre el momento del habla y la acción marcada por el pretérito hay un momento antes del que se realizó la acción (Stanojčić i Popović 2004: 386). También se reconoce por conectores de tiempo onda, tada, etc.

- Pričala mi je o njemu, bio je on (tada) sasvim drugi čovek.

- Me hablaba de él, era (en aquel entonces) un hombre completamente distinto.

En este ejemplo, el uso del pretérito imperfecto en español se relaciona con la descripción de ciertas características que eran válidas en el pasado.

\subsection{Pretérito cualitativo (kvalitativni perfekat)}

Indica una condición que ha surgido en el pasado y que se nota en un período pasado determinado o en el momento del habla (Stanojčić i Popović 2004: 387).

- U uglu sobe stajala je stolica, a sa zida je visio isti onaj stari sat.

- En la esquina de la habitación había una silla, y en la pared estaba colgado aquel mismo reloj antiguo.

Como el pretérito cualitativo es de carácter descriptivo, y como en el ejemplo anterior se describe una determinada situación del pasado, el pretérito imperfecto será la forma más adecuada para transmitir el mismo mensaje en español.

\subsection{Pretérito modal (modalni perfekat)}

Indica la actitud del hablante hacia una determinada acción no realizada (Stanojčić i Popović 2004: 387). Dependiendo del significado de tal acción, puede referirse a:

a) Acción, condición u ocurrencia condicional

- Da smo došli na vreme, videli bismo taj film.

- Si hubiéramos llegado al tiempo, habríamos visto esa película. 
Como se trata de una acción del pasado no realizada dentro de una oración condicional, será traducida al español usando el pretérito pluscuamperfecto de subjuntivo. Dentro de estas acciones condicionales en serbio, también se incluyen aquellas que cargan con cierta dosis de remordimiento o arrepentimiento (da + pretérito). En español, aparte del mencionado pluscuamperfecto de subjuntivo, este tipo de mensajes se puede transmitir recurriendo al infinitivo perfecto:

- Da sam ranije saznao za to!

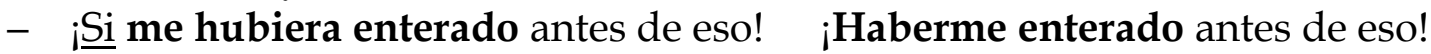

b) Otras acciones hipotéticas

- Ako su mene slagali, lažem i ja vas.

- Si me mintieron a mí, os miento yo a vosotros también.

Las oraciones que conllevan cierta dosis de incertidumbre o suposiciones del pasado, no se expresan en serbio a través de tiempos verbales, sino utilizando otros elementos lingüísticos (rečce, verbos incompletos). En español, en tales situaciones se utilizará el futuro perfecto o condicional:

- Gde su mi ključevi? - Mora da si ih ostavio na stolu.(acción de un pasado reciente)

- ¿Dónde están mis llaves? - Las habrás dejado en la mesa.

- Koliko li je Huan platio svoj novi auto? (acción de un pasado terminado)

- ¿Cuánto le costaría/habrá costado a Juan su nuevo coche?

c) Acciones que se anuncian como una orden

- Deco, da ste se odmah smirili!

- Niños, ¡qué os calméis enseguida! ¡Niños, calmaos enseguida!

El imperativo en español siempre está ligado al presente, porque una orden, mandato o petición siempre se da en el momento presente, aunque su ejecución se refiera al futuro (RAE 1999: 55). Además del imperativo afirmativo («calmaos»), en español las órdenes y los deseos a menudo se expresan usando la construcción «qué + presente de subjuntivo», como se indica en el ejemplo anterior («qué os calméis»). 


\section{Pretérito truncado y sus equivalentes en español}

El pretérito truncado (krnji perfekat) es característico del idioma serbio y se reconoce por la ausencia del verbo auxiliar jesam, por lo que representa una categoría sintáctica especial (Stanojčić i Popović 2004: 388). Por lo tanto, debe distinguirse claramente de los casos en los que, debido a la enumeración en una oración o en varias oraciones consecutivas, aparece como un adjetivo verbal (radni glagolski pridev):

A on gledao, gledao i na kraju rešio $\neq$ A on je gledao i na kraju (je) rešio da da kupi. kupi.

Como el pretérito truncado no tiene un equivalente directo en español, le corresponderán diferentes tiempos verbales, dependiendo de la situación del habla, la función que desempeña y el enunciado específico. Básicamente, se utilizarán las mismas formas que reemplazarían al pretérito completo dependiendo de su uso sintáctico.

\subsection{Pretérito truncado relativo (relativni krnji perfekat)}

Este tipo del pretérito truncado es el más común en el idioma serbio, especialmente en la narración.

- Zima je već odavno; zahladnelo, pao sneg...

- Hace mucho que estamos en invierno; hace más frio, ha nevado...

Como puede observarse, el problema del aspecto gramatical perfectivo del verbo zahladneti, en este caso también se ha resuelto utilizando otros medios lingüísticos, concretamente en este caso, la colocación «hacer frío». Sin embargo, ha sido con el uso del cuantificador «más» que se ha logrado responder plenamente al significado del verbo zahladneti, porque sin su presencia, la expresión en español sería equivalente a la serbia hladno je. Además, en español se ha utilizado el presente porque se concluye del contexto que el invierno no ha terminado, es decir, la acción expresada por la colocación coincide con el momento de habla. El uso del pretérito imperfecto, en cambio, significaría que la acción ya no está en curso («hacía más frío el año pasado»).

La construcción pao sneg se ha traducido con el pretérito perfecto próximo, ya que el remoto implicaría una especie de certeza de que la nieve ya no caerá, lo que no se puede concluir sobre la base del contexto dado. Por supuesto, en las zonas de habla hispana donde este tiempo verbal ha dejado de utilizarse, se utilizará la forma «nevó». 


\subsection{Pretérito truncado indicativo (indikativni krnji perfekat)}

El uso de este tipo de pretérito, también es común, ya sea en el estilo conversacional o periodístico. Su principal característica es que implica una nueva información para el oyente / lector (Stanojčić i Popović 2004: 388).

- Marko, došao Filip! Otvori mu vrata.

- Marco, ¡ha llegado Felipe! Ábrele la puerta.

(pasado reciente)

Los siguientes ejemplos afirman el hecho de que el pretérito truncado se utiliza a menudo en los titulares de los artículos periodísticos, pero también que en los mismos casos en español se suele utilizar el presente. Por supuesto, esta no es la única solución, sí tiene una amplia presencia en el estilo periodístico, ya que de esa manera se logra la expresividad de la expresión y atrae la atención del lector. A continuación, se muestran algunos ejemplos de los titulares en serbio y español:

PALE CENE STANOVA («Cene stanova pale...» 2011)

BAJA EL PRECIO DE LOS PISOS (De la Vega 2013)

ŠEIK IZ EMIRATA DOPUTOVAO U BEOGRAD (Vukotić 2013)

EVO MORALES LLEGA A MADRID («Evo Morales llega a Madrid...» 2012)

U MOSKVI TEMPERATURE DOSTIGLE 35 STEPENI («U Moskvi temperatura...» 2012)

JUNIO LLEGA CON TEMPERATURAS DE 38 GRADOS (Navarcorena 2012)

\subsection{Pretérito truncado como modo (krnji perfekat kao modus)}

Puede indicar la actitud personal del hablante, y en este contexto, se refiere a los deseos, suposiciones y creencias del hablante dentro de un enunciado particular. Dado que estas son las características principales del subjuntivo en español, será precisamente este modo el que se utilizará como equivalente a este pretérito truncado en el idioma serbio:

- Živeli mladenci!

- ¡Vivan los novios!

- To će uraditi makar glavu izgubio.

- Lo hará aunque le costara la vida.
- Bežao, ne bežao, nećes pobeći!

- Huyas o no huyas, no podrás escaparte. 
A diferencia de otros ejemplos, en este último se utilizó el subjuntivo imperfecto, porque la acción a la que se refiere es potencial, esto es, su realización no es segura.

\subsection{Pretérito truncado gnómico (gnomski krnji perfekat)}

Se usa en proverbios y refranes. Un proverbio adecuado en español no tiene por qué contener la misma forma verbal que en serbio, pero debe transmitir el mismo mensaje, incluso si se basa en una expresión completamente diferente:

- Pošto kupio, po to i prodao.

- Quien mal anda, mal acaba.

\section{A modo de conclusión}

A lo largo del presente estudio, describiendo cada uno de los usos del pretérito en serbio y comparándolo con el sistema verbal español, aparecieron prácticamente todos los tiempos verbales, algunos de ellos más de una vez, siendo el futuro simple de indicativo y el infinitivo los únicos que no actuaron como un sustituto adecuado al pretérito en serbio.

Asimismo, las perífrasis verbales juegan un papel importante entre las formas correspondientes al pretérito serbio. Algunas de ellos se han analizado en el artículo: estar + gerundio (duración de la acción), ir (en el pretérito imperfecto) + a + infinitivo (acción no realizada), acabar de + infinitivo (la acción que tuvo lugar justo antes del momento del discurso) y quedar(se) + participio pasado (acción completada). Sin embargo, existen otras paráfrasis que, utilizadas en un contexto y tiempo adecuados, sirven para expresar lo mismo que comunica el pretérito en serbio: soler + infinitivo, andar + gerundio, llevar + gerundio, pasar + gerundio, seguir + gerundio, ir + gerundio, volver + a + infinitivo, etc.

Todo esto apunta a que los roles que desempeña el pretérito en serbio están tan extendidos que, para expresar todas esas funciones, en español se recurrirá a la mayoría de los tiempos y las perífrasis verbales.

Esto, a su vez, justifica el planteamiento inicial de asignarle al presente estudio un rol didáctico, de manera que los ejemplos analizados puedan servir como punto de partida para diseñar actividades para estudiar distintas formas de expresar el pretérito serbio en español. 


\section{BIBLIOGRAFÍA}

Bajić Nikolić, Dragana, y María Ángeles Alonso Zarza. «Acerca de los problemas de la traducción de los sistemas temporo-aspectuales en serbocroata y en español.» Traducción y Multiculturalidad, María Pilar Blanco García y Pilar Martino Alba (Eds.). Madrid: Instituto Universitario de Lenguas Modernas y Traductores de UCM, 2006. 281-290. Web. 20 de nov de 2020.

«Cene nekretnina pale 40 odsto, kupaca sve manje.» Blic, 28 Jun. 2011. Web. 10 Nov 2020.

De la Vega, Inmaculada. «El precio de los pisos baja más del 33\% hasta estar en valores de inicios de 2003.» El País, 2 Ene. 2013. Web. 10 Nov 2020.

Díaz Rubio y Carmena, Manuel María. Análisis lógico-gramatical. Toledo: Librería de Fando y hermano, 1885. Impreso.

«Evo Morales llega a Madrid, visita a Rajoy, va al cine y se marcha a Barcelona.». El País, 8 Dic. 2012. Web. 10 Nov 2020.

Garcés, María Pilar. Las formas verbales en español, valores y usos. Madrid: Verbum, 1997. Impreso.

Navarcorena, M. «Junio llega con temperaturas de 38 grados y obliga a activar la alerta.» El Periódico de Aragón, 2 Jun. 2012. Web. 10 Nov 2020.

Pavón Lucer, María Victoria. Gramática práctica del español. Madrid: Espasa Calpe, 2007. Impreso.

Real Academia Española. Gramática de la lengua castellana [Transcripción]. Alicante: Biblioteca Virtual Miguel de Cervantes, 1999. Web. 20 Nov 2020.

Stanojčić, Živojin, i Ljubomir Popović. Gramatika srpskog jezika. Beograd: Zavod za udžbenike i nastavna sredstva, 2004. Štampano.

«U Moskvi temperatura dostigla 35 stepeni.» Blic, 3 Jun. 2012. Web. 10 Nov 2020.

Vukotić, D. «Naslednik prestola Emirata doputovao u Beograd.» Politika, 9. jan. 2013. Web. 10 Nov 2020. 